\title{
A NUMERICAL STUDY OF SHORT RESIDENCE TIME FCC RISER FLOWS WITH A NEW FLOW/KINETICS MODELING TECHNIQUE*
}

\author{
S.L. Chang, S.A. Lottes, C.Q. Zhou**, and M. Petrick \\ Argonne National Laboratory \\ 9700 South Cass Avenue \\ Argonne, IL 60439 \\ ** Purdue University Calumet \\ Hammond, IN 46323

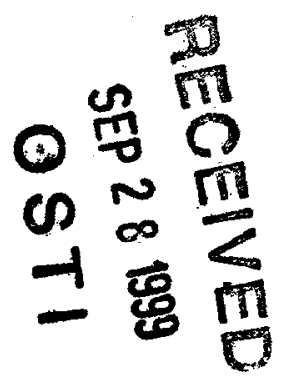

The submitted manuscript has been created by
the University of Chicago as Operator of Argonne
National Laboratory ("Argonne") under Contract
No. W-31-109-ENG-38 with the U.S. Department
of Energy. The U.S. Govemment retains for itself,
and others acting on its behalf, a paid-up,
nonexclusive, irrevocable worldwide license in
said article to reproduce, prepare derivative
works, distribute copies to the public, and pertorm
publicly and display publicly, by or on behalf of
the Government.

submitted to

1998 International Mechanical Engineering Congress and Exposition,

Nov. 15-20, 1998, Anaheim, CA

sponsored by

the K-11 committee of the Heat Transfer Division of ASME.

* Work supported by U.S. Department of Energy, Assistant Secretary for Energy Efficiency and Renewable Energy, under Contract W-31-109-ENG-38. 


\section{DISCLAIMER}

This report was prepared as an account of work sponsored by an agency of the United States Government. Neither the United States Government nor any agency thereof, nor any of their employees, make any warranty, express or implied, or assumes any legal liability or responsibility for the accuracy, completeness, or usefulness of any information, apparatus, product, or process disclosed, or represents that its use would not infringe privately owned rights. Reference herein to any specific commercial product, process, or service by trade name, trademark, manufacturer, or otherwise does not necessarily constitute or imply its endorsement, recommendation, or favoring by the United States Government or any agency thereof. The views and opinions of authors expressed herein do not necessarily state or reflect those of the United States Government or any agency thereof. 


\section{DISCLAIMER}

Portions of this document may be illegible in electronic image products. Images are produced from the best available original document. 


\title{
A NUMERICAL STUDY OF SHORT RESIDENCE TIME FCC RISER FLOWS WITH A NEW FLOW/KINETICS MODELING TECHNIQUE*
}

\author{
S.L. Chang, S.A. Lottes, C.Q. Zhou*, and M. Petrick \\ Argonne National Laboratory \\ 9700 South Cass Avenue \\ Argonne, lllinois 60439 \\ *Purdue University Calumet \\ Hammond, Indiana 46323
}

\begin{abstract}
Fluid Catalytic Cracking (FCC) technology is the most important process used by the refinery industry to convert crude oil to valuable lighter products such as gasoline. New and modified processes are constantly developed by refinery companies to improve their global competitiveness and meet more stringent environmental regulations. Short residence time FCC riser reactor is one of the advanced processes that the refining industry is actively pursuing because it can improve the yield selectivity and efficiency of an FCC unit. However, as the residence time becomes shorter, the impact of the mixing between catalyst and feed oil at the feed injection region on the product yield becomes more significant. Currently, most FCC computer models used by the refineries perform sophisticated kinetic calculations on simplified flow field and can not be used to evaluate the impact of fluid mixing on the performance of an FCC unit. Argonne National Laboratory (ANL) is developing a computational fluid dynamic (CFD) code ICRKFLO for FCC riser flow modeling. The code, employing hybrid hydrodynamic-chemical kinetic coupling techniques, is used to investigate the effect of operating and design conditions on the product yields of FCC riser reactors. Numerical calculations were made using the code to examine the impacts of the operating and design conditions on the product yields. The controlling parameters under investigation include the residence time, reaction temperature, and catalyst/oil ratio. This paper describes the CFD code, presents computational results, and discusses the effects of operating conditions on the performance of short residence time FCC riser reactors.
\end{abstract}

\section{NOMENCLATURE}

$a_{i, j} \quad$ stoichiometric coefficients

C coke species

E activation energy $(\mathrm{J} / \mathrm{kmol})$ $f_{\mathrm{i}} \quad$ species concentration $(\mathrm{kg} / \mathrm{kg})$

$\mathbf{k}_{\mathrm{i}} \quad$ reaction rate parameter $(1 / \mathrm{s})$

$\mathrm{m}_{\text {evp }}$ droplet evaporation rate $\left(\mathrm{kg} / \mathrm{s} / \mathrm{m}^{3}\right)$

$n_{k} \quad$ droplet or particle number density (number of droplets $/ \mathrm{m}^{3}$ )

$\mathrm{R}$ gas constant (J/kmol-K)

$S \quad$ Source term of a governing equation

T temperature (K)

$t$ time (s)

u velocity component in the $x$-direction $(\mathrm{m} / \mathrm{s})$

$v$ velocity component in the y-direction $(\mathrm{m} / \mathrm{s})$

x $\quad x$ coordinate $(\mathrm{m})$

$y \quad y$ coordinate $(\mathrm{m})$

\section{Greek Symbols}

$\alpha \quad$ catalyst decay parameter

$\phi \quad$ catalyst decay function

$\Gamma \quad$ effective diffusivity (pa-s)

$\boldsymbol{\theta}$ gas void fraction

$\rho \quad$ gas density $\left(\mathrm{kg} / \mathrm{m}^{3}\right)$

$\xi \quad$ general variable for $1, u, v, h, f, k$ or $\varepsilon$

\section{Subscripts}

c condensed phase, droplet or particle

ck coke

d droplet

$\mathbf{k} \quad$ size group $\mathbf{k}$ of droplets or particles

$\ell \quad$ light oil

o feed oil

p particle

s solid

$t$ turbulent

$\delta \quad$ slip property

$\xi$ general variable for $1, u, v, h, f, k$ or $\varepsilon$ 


\section{INTRODUCTION}

The rapid advance in the performance and amount of memory and secondary storage available in modern computers has made possible a concurrent advance in computational fluid dynamics (CFD) and in computational approaches to complex chemical kinetics. Computational fluid dynamics (CFD) has been used to enhance the understanding of hydrodynamics, thermodynamics, and multi-phase flow interactions. In many reacting flow systems of practical interest, the fluid dynamics has a significant impact on the chemical kinetics because temperature, mixture composition, degree of mixedness, catalyst concentration and activity (when present), and other flowfield properties relevant to the process of chemical reaction change from point to point throughout the flowfield of a chemical reactor, such as an FCC riser. In general, however, the length and time scales of fluid dynamics and chemical reaction can be different by many orders of magnitude. These scale differences have made the coupling of detailed kinetics and fluid dynamics in process computations of reacting flow system very difficult. For the past 20 years, many CFD codes have been developed and evolved greatly with the advancement in both numerical techniques and computer hardware. CFD applications were extended from simple laboratory-type to complex industrial-type flow systems. Computer simulation is regarded as an effective and cost-saving tool to further improve the performance of flow systems. When extended to reacting flow systems the potential benefits of CFD are multiplied greatly.

Several CFD codes have been developed at Argonne National Laboratory (ANL) to study flow characteristics of various engineering systems. Among them, the ICOMFLO (Chang and Lottes, 1993) and ICRKFLO (Chang and Lottes, 1995) codes were developed for multiphase reacting flows using very stable reduced reaction integral (as opposed to differential) chemical kinetics models. The codes have been used to simulate multiphase reacting flows in fluid catalytic cracking (FCC) reactors (Chang et al, 1996), coal-fired combustors (Chang and Lottes, 1993), internal combustion engines (Chang and Wang, 1987), and air-breathing jet engines (Zhou and Chiu, 1983). The codes were constantly validated when experimental data were available for comparisons (Chang et al., 1995, Chang and Lottes, 1993, and Lottes and Chang, 1991).

In most reacting flows, there are complex chemical reactions involving many species. Researchers in the field of chemical kinetics (Nigam and Klein, 1993, and Quann and Jaffee, 1996), to name only a few) have been developing ways to approach chemical kinetics computation and model building for complex reaction systems with large numbers of reactants (hundreds to thousands), such as those found in petroleum refining. CFD calculations of a reacting flow with many reacting species are often troubled by numerical stiffness problems. A general approach to coupling CFD computations with complex chemical kinetic computations has been developed for application to FCC riser simulation by the authors of this paper.

This approach to CFD-kinetics coupling also incorporates a generalized lumped chemical kinetics model that can be adapted to specific FCC riser systems using measured product yields and operating condition data from those systems. In the current work, twenty petroleum lumps including coke are used in the kinetics model, however, the number of lumps can be expanded into hundreds or even more. Using this general kinetics model and a kinetics model parameter generation algorithm, transport and mixture concentrations of many reacting species can be computed for in an FCC riser reactor.

\section{THEORETICAL APPROACH}

An FCC riser is used to convert crude oil to more valuable lighter oil products, such as gasoline. A riser has two major types of inlets: one for crude oil and the other for hot catalyst particles. The crude oil is injected in a liquid spray. Heat transferred from the hot particles vaporizes the liquid droplets. Then, oil vapor reacts on catalyst surfaces. The crude oil is a mixture of many oil species and many more are generated in the cracking reactions in the FCC riser.

An FCC riser flow contains three phases, a gas phase carrier medium, feed oil droplet phase, and catalyst particle discrete phases. All phases undergo convective, diffusive, and turbulent transport in a reacting flow mixture of chemical species with momentum, heat, and mass transfer between the phases. Because of the wide range of time and length scales, as much as 10 orders of magnitude, in these many interacting processes within the flow, solving all the governing equations with a single integrated computational algorithm is currently an intractable problem. An approach to modeling such complex flow systems, which can successfully compute the enajor characteristics of these flows and selected characteristics in finer detail, has been developed. This approach employs the primary governing physics with process detail reduction using experimentally verified models for some processes where process detail may not be of interest.

The computation of the system process state is split into stages, where subsequent stages employ computed results from a previous stage. In this FCC riser application, the first stage computation is a CFD computation that uses a reduced four lump chemical kinetics model.

The second stage computation employs process detail model expansion for either of two types of computations. The first type of second stage computation uses experimental petroleum cracking product yields and first stage computation local flow field data, such as temperature, to find a set of kinetic constants for expanded detailed chemical kinetic computations that meet minimum deviation criteria for the experimental data. The second type of second stage computation also uses local flowfield state data from the first stage computation and combines it with the expanded kinetic model and constants determined from the first type of second stage computation to predict local detailed species concentrations, reaction rates, and ultimately product yields for the FCC riser reactor over an operating range of interest.

This kinetics-flow coupling model can be characterized as using a kinetic model generator which implicitly employs flowfield structure and thermodynamic state structure within the reactor in the generation of the kinetic model. This approach is a different, but complementary approach to the kinetic model generators being developed by other researchers (Nigam and Klein, 1993, and Quann and Jaffee, 1996) who are attempting to incorporate chemical species structure information into the kinetic model generation process. When hydrodynamics and multiphase heat, momentum, and mass transfer can have a major impact on the performance of an FCC reactor unit, the best way to generate a kinetics model is to use the hydrodynamics simulation itself to provide detailed flowfield structure to the kinetics model generator. In the current approach the chemical kinetics and flow coupling is guaranteed to be stable and adequately accurate for the cases based on experimental data. If it were not, the kinetics model generation would not have been successful. Given that the generated kinetics model is stable and matches the data from a set of experiments within deviation tolerances, the operating condition space 
can be investigated in a reasonable neighborhood of the experimental data points using the coupled kinetics-flow model to search for various types of operating optimums or operating conditions to meet specific product yield goals with a high probability of success.

\section{Flow Computation Using A Reduced KInetlc Model}

In the application presented here, the local flow and thermodynamic variable field is computed in the first stage over the entire interior of an FCC riser. All the governing transport and conservation equations for the three phases are elliptic-type partial differential equations. For convenience in numerical formulation, they are arranged in a common form. For gas phase, this form is.

$$
\frac{\partial}{\partial \mathrm{x}}\left(\theta \rho u \xi-\Gamma_{\xi} \frac{\partial \xi}{\partial \mathrm{x}}\right)+\frac{\partial}{\partial y}\left(\theta \rho v \xi-\Gamma_{\xi} \frac{\partial \xi}{\partial y}\right)=S_{\xi}
$$

in which $\xi$ is a general flow property, $\mathrm{x}$ and $\mathrm{y}$ are coordinates, $\theta$ is gas volume fraction, $u$ and $v$ are velocity components, $\Gamma$ is effective diffusivity (calculated from both laminar and turbulent viscosities and an appropriate nondimensional scaling factor), and $S_{\xi}$ is the sum of source terms.

For droplet and solid phases, the Eulerian approach is employed, and the formulation is:

$$
\frac{\partial}{\partial x}\left(n_{k} u_{d, k} \xi-\Gamma_{\xi} \frac{\partial n_{k} \xi}{\partial x}\right)+\frac{\partial}{\partial y}\left(n_{k} v_{d, k} \xi-\Gamma_{\xi} \frac{\partial n_{k} \xi}{\partial y}\right)=S_{\xi}
$$

in which $\xi$ is a general droplet or particle property, $\mathrm{n}_{\mathbf{k}}$ is droplet or particle number density of kth size group, $u_{d, k}$ and $v_{d, k}$ are droplet or particle velocity components of $k t h$ size group in the $\mathrm{x}$ and $\mathrm{y}$ direction respectively, $\Gamma$ is droplet or particle diffusivity resulting from interaction with turbulence in the gas phase (Lottes and Chang, 1991), and $S_{\xi}$ is the sum of source terms.

The SIMPLER algorithm (Patankar, 1980) adapted for multiphase flow with an enhanced outflow boundary treatment is employed to solve the gas phase continuity and momentum equations in the form of Eq.(1). This algorithm provides a numerically stable way to handle pressure-velocity coupling in the flowfield.

Phenomenological models are used to characterize multiphase cracking flow in the FCC unit, including interfacial drag and heat transfer, droplet dispersion and evaporation, two-parameter multiphase turbulence, coke formation, and lumped integral reaction models. A brief description of these models is given in the following. A more detailed description of the models can be found in a previous publication (Chang et al., 1996).

Hot catalyst particles transfer heat to oil droplets for vaporization. An interfacial model uses empirical correlations to calculate interfacial momentum and heat transfer. A particle-solid interaction model was developed to account for particle-particle and particle-wall collisions in regions of high particle volume fraction.

The droplet dispersion and evaporation model divides the size distribution of oil droplets into a number of size groups, calculates the evaporation rates of the droplets, and translates the evaporation rates into a droplet size distribution shift.

The commonly used $\mathrm{k}-\varepsilon$ turbulence model was modified to include the effects of interaction of both the droplet and particle phases with the gas phase turbulence. The turbulent diffusivity is assumed to be a function of turbulent kinetic energy and dissipation rate. The gas phase turbulence model was extended for multiphase flows by accounting for turbulent dispersion of particles.

The first stage of a computation uses a reduced lumped cracking reaction model, based on lumped kinetics modeling works by Weekman and Nace (1970) and by Dave et al. (1993) and an integral reacting-flow time-scale-conversion method (Chang and Lottes, 1993), for the simulation of FCC riser flows.

The model includes 4 lumped oil components and 2 cracking reactions. Oil components are divided into 4 major lumps: feed oil, light oil, dry gas, and coke (Dave et al., 1993). One cracking reaction converts feed oil to light oil, dry gas, and coke; and the other converts light oil to dry gas and coke. These reactions are denoted as follows:

$$
P_{0} \longrightarrow a_{1} P_{\ell}+a_{2} P_{g}+a_{3} C_{k}
$$

$$
P_{\ell} \longrightarrow b_{1} P_{g}+b_{2} C_{k}
$$

where $P_{o}, P_{b}, P_{g}, C_{k}$ represent feed oil, light oil, dry gas, and coke, respectively, and stoichiometric coefficients, $a_{1}, a_{2}, a_{3}, b_{1}$, and $b_{2}$, are expressed in mass fractions. Reaction rates of these reactions are expressed in Arrhenius formulae as,

$$
\begin{aligned}
& \frac{\mathrm{df}_{\mathrm{o}}}{\mathrm{dt}}=-\mathrm{k}_{\mathrm{o}, \mathrm{a}} \exp \left(-\mathrm{E}_{\mathrm{a}} / \mathrm{RT}\right) \phi \mathrm{f}_{\mathrm{o}}^{2} \\
& \frac{\mathrm{df}_{\ell}}{\mathrm{dt}}=-\mathrm{k}_{\mathrm{o}, \mathrm{b}} \exp \left(-\mathrm{E}_{\mathrm{b}} / \mathrm{RT}\right) \phi \mathrm{f}_{\ell}
\end{aligned}
$$

in which, $k_{0}$ is the rate constant, $E$ is activation energy, and $\phi$ is a catalyst decay function defined as,

$$
\phi=\exp \left(-t_{c} \alpha_{o}\right)
$$

To obtain integral model source terms, Eqs.(3) and (4) are integrated and then the integrals are differentiated with respect to distance in the flow direction multiplied by the flow velocity which yields reaction rate source terms that implicitly take into account concentration and temperature gradients across computational cells and therefore bridge the difference between the reaction and flow time scales (Chang and Lottes, 1993).

The presence of large numbers of both source and sink terms in coupled nonlinear partial differential equations greatly increases the probability of either divergence through source feedback between equations or endless numerical oscillation (failure to converge) due to feedback loops between sources and sinks. Using a reduced kinetic model for flow calculations greatly reduces the possibility that either of these numerical problems will arise in determining the structure and state of the flowfield.

The use of a reduced kinetic model is reasonable for flowfield calculations because the primary effects of reaction on the flowfield are due to the heat released or absorbed by reaction and changes in mixture molecular weight due to reaction. The heat rates are needed to ultimately determine the temperature fields. Using a reduced 
kinetic model coupled with computational fluid dynamics to calculate a detailed local temperature field is certainly much better than using an assumed axial temperature profile (between known inlet and exit temperatures) and usually an assumed uniform radial temperature profile to do subsequent kinetics calculations. Similar conclusions apply to molecular weight, which affects the determination of the detailed local gas phase density field.

The use of computational fluid dynamics to obtain the detailed local velocity, temperature, density, and gas phase volume fraction fields is necessary to enable computation of detailed transport and local reaction of a greatly expanded chemical kinetics model including from tens to thousands of chemical species. Obtaining experimental data for these flow system variables at thousands of different points in the interior of an FCC reactor is simply not feasible for a number of reasons. Even for computational code validation, such data is often difficult to obtain in a small number of test locations in laboratory scale units. The harsh environments in FCC reactors also tend to make such data acquisition either impossible or to require very expensive data acquisition techniques.

\section{Generic Detailed Kinetics Model Expansion}

Because of the very large number of chemical species involved in FCC refining of crude oil feed stocks, some form of lumping into mixture lumps is almost always employed even for detailed calculations involving a very large number of lumps. The detailed kinetics lumping model is frequently based on a property that is easily related to refinery products, such as boiling point ranges, molecular weight ranges, or carbon number ranges. Chemical structure based approaches, such as those of Nigam and Kline (1993) or Quann and Jaffee (1996) attempt to lump species into groups that will follow the same type of reaction pathway or have structure similarities that provide a way to estimate lump thermodynamic properties. In the general detailed model presented here the common approach of lumping by boiling point bands is used. For purposes of illustration the spectrum of feed oil and products is divided into twenty boiling point lumps. Each lump is referred to as a subspecies. Any number of minor kinetic species can be selected for a transport calculation. For convenience of discussion, 19 oil vapor species $\left(P_{j}, i=2,20\right)$ and $a$ byproduct coke $\left(C_{k}\right)$ are used here. The molecular weight of $P_{i}$ increases for larger $i$. Heavier species $P_{i}$ is cracked into lighter species $P_{j}, j=2, i-$ 1 , in a reaction (c).

$$
P_{i} \stackrel{k_{i}}{\longrightarrow} \sum_{j=2}^{i-1} a_{i, j} P_{j}+a_{i, 1} C_{k} \quad i=3,20
$$

in which $a_{i j}$ 's are stoichiometric coefficients and $k_{i}$ 's are the reaction rates. Ahrrenius type formula, Eq.(14), is used to represent reaction rate of the ith cracking reaction.

$$
\begin{aligned}
k_{i}=k_{D, i} & \exp \left[-E_{i} / R\left(\frac{1}{T}-\frac{1}{T_{r}}\right)\right] \quad i=3,20 \\
& \times \theta_{s} \exp \left(-\alpha_{i} f_{c k}\right)
\end{aligned}
$$

in which, $k_{o, i}$ is the rate constant, $E_{i}$ is the activation energy, and $\alpha_{i}$ is deactivation coefficient of the ith cracking reaction, and $\theta_{p}$ is the catalyst volume fraction, $T_{r}$ is a reference temperature, and $f_{c k}$ is coke concentration.

\section{Generic Subspecies Kinetics and Transport Model}

A subspecies $P_{i}$ is generated from the evaporation of oil droplets and/or the cracking reactions. The subspecies generated is transported by convection and diffusion of the flow. The governing equation of the species concentration $f_{\mathrm{p}, \mathrm{i}}$ can be written as,

$$
\begin{gathered}
\frac{\partial}{\partial x}\left(\theta \rho u f_{p, i}-\Gamma_{f} \frac{\partial f_{p, i}}{\partial x}\right)+\frac{\partial}{\partial y}\left(\theta \rho v f_{P, i}-\Gamma_{f} \frac{\partial f_{P, j}}{\partial y}\right) \\
=f_{i, o} \dot{m}_{\text {evp }}+\sum_{j=i+1}^{20} a_{j i} k_{j} f_{P, j}-\sum_{j=2}^{i-1} a_{i j} k_{i} f_{p, j}
\end{gathered}
$$

The $i$ index in Eq.(7) ranges from 2 to 20 giving a transport equation with reaction for each of the subspecies lumps except coke, which can be calculated by doing a mass balance. The summation terms in Eq.(7) are taken to drop out when the lower or upper index is out of range, which accounts for the lowest and highest boiling point lumps, the highest having no reaction sources and the lowest having no reaction sinks.

After the first stage of computation using the reduced four lump kinetic model to obtain the local flowfield structure and state, the only unknowns in the set of subspecies transport equations, Eq.(7) are the local subspecies concentrations, $f_{p, i}$, for $i=2$ to 20 . Eq.(7) is solved for each of the subspecies concentrations over the flowfield. The computation can be run in a kinetic parameter/data matching mode, using both the CFD flowfield data from the first stage computation and measured product yield data to determine the set of preexponential kinetic constants and the activation energies for the seventeen $k_{i}$. Using this methodology, the generic subspecies kinetics model can be adapted to specific FCC risers for a specific catalyst and crude oil feed, assuming that the catalyst and feed properties are given. Using the CFD code in the parameter/data matching mode requires product yield data sets for a set of different operating conditions in the operating ranges of interest. At a minimum data for five cases are needed including a reference case, a case at high temperature, a case at low temperature, a case at high catalyst to oil ratio, and a case at low catalyst to oil ratio. Additionally, data for a number of different cases in the neighborhood of the operating ranges should be provided to validate the kinetic model parameters for the given FCC riser, catalyst, feed and operating condition window.

\section{NUMERICAL SCHEME}

A control volume approach is used to convert the governing equations to algebraic equations on a discretized grid system. The grid system is staggered, consisting of three grids: an x-momentum grid for the gas phase $x$-momentum equation, a gas phase $y$-momentum grid, and a scalar gird for all the other equations. The algebraic equations are solved iteratively with the boundary conditions.

There are three major iteration routines in the multiphase reacting flow simulation. The first is for the gas flow calculation, the second is for the droplet and particle flow calculation, and the third is for the subspecies reaction and transport calculation. In the calculations, Patankar's SIMPLER computational scheme (1980) is used to solve the pressure linked momentum equations.

Grid sensitivity studies were conducted to choose the final grids which gave independent numerical results to three significant decimal digits upon further grid refinement in order to conserve computational 
time and still provide adequately accurate results. An important feature of the control volume approach is that it is conservative in terms of mass, energy, species, and all variables solved for via the transport equations, both locally and globally to a very high degree regardless of grid size. This feature helps to ensure that results are physically realistic regardless of grid size and that trends in parametric studies are relatively independent of grid size even for relatively coarse grids. Little would be gained therefore in attempting to refine the grid to make results grid independent to more than 3 or 4 significant digits.

The simulated riser flow includes four gas species, five droplet size groups, a single particle size group, and a coke species carried by particles. In this computer code, a calculation is considered to have converged if the local and global mass balances of the three phases are smaller than a set of predetermined criteria. For this simulation, convergence criteria, defined by average mass residual of all computational cells, are $10^{-10}$ (in dimensionless form, normalized by the inlet mass flow rate) for the gas phase and $10^{-8}$ for both the liquid and solid phases. Generally in this application, with reasonable boundary conditions (inlet flow rates etc.), a converged solution can be obtained in about 700 global iterations. Each global iteration includes 10 gas phase iterations and 3 liquid and solid phase iterations. On a Pentium ${ }^{\mathrm{TM}}$ II 300 computer with 64 megabytes of random access memory, using a 32-bit FORTRAN compiler, this computation takes about 4 hours. The subspecies calculation is generally much faster than the flow calculation depending on the number of subspecies to be calculated.

\section{APPLICATION EXAMPLES WITH EMPHASIS ON SHORT RESIDENCE TIME CONDITIONS}

\section{Sample Generic Subspecies Computation}

An arbitrary feed of the subspecies lumps primarily concentrated in the boiling point range $700 \mathrm{~K}$ to $900 \mathrm{~K}$ was chosen for a sample generic subspecies computation. A typical size laboratory scale riser geometry was set up with a computational grid for the sample simulation. In this geometry lift gas and a feed oil droplet spectrum entered the riser, catalyst particles entered from the side. Details of the simulation setup are not of prime importance, because the simulation is meant to be a generic base that can be adapted to particular riser geometries, crude oil feeds, and catalyst properties. The catalyst to oil ratio was approximately 8 . The generic kinetics model assumes an uniform cracking probability from any particular lump into two lumps whose molecular weights sum to the molecular weight of reactant lump. Because of the side injection of catalyst into the riser, the flow conditions across the riser cross-section which may affect cracking rates are not uniform.

Figure 1 shows the feed distribution among 19 boiling point lumps and the resulting yield distribution at the riser exit plane over the same 19 boiling point lumps in terms of cracking product vapor mass fraction. The yield curve has the general shape a typical yield curve for a laboratory scale riser without local peaks and dips that would characterize the chemistry of a particular feed and catalyst. The generic model can be set up for a specific FCC system very quickly if yield data sets are available for a relatively small matrix of operating conditions along with riser geometry and material properties.
Figure 2 shows the comparison of yield data with computed yield results over a carbon number lumping range. Agreement with measured results is excellent.

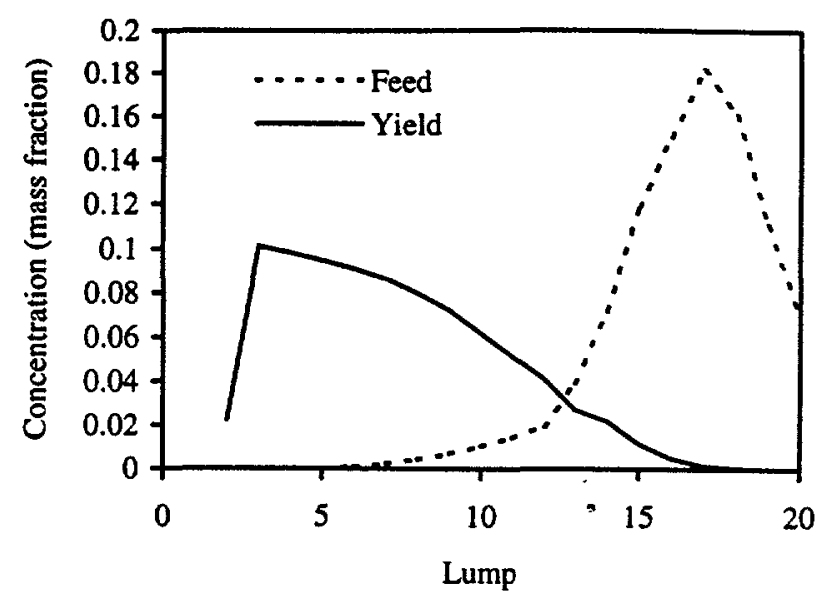

Figure 1 Pure Generic Model Simulation Feed to Product Yield

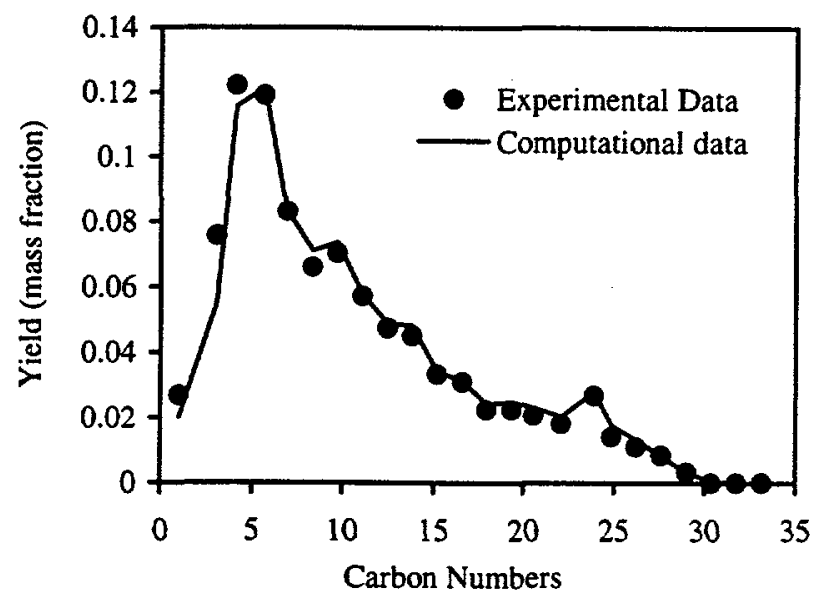

Figure 2 Comparison of Data and Computational Yield Results When generic model is calibrated for a real riser.

\section{Residence Time Effects Based on Different Riser Lengths}

A study was conducted using these new computational techniques varying both FCC riser length and the catalyst to oil ratio (C/O). The C/O ratio is thought to be one of the most significant parameters affecting product yields in short residence time regimes. Figures 3 and 4 show the results over an entire 20 lump model product yield range. Results for three riser lengths are shown. All other conditions being roughly equal, riser length correlates with riser residence time, although the relationship is not purely linear because riser residence time is affected by feed oil vaporization time. Therefore, the long, mid-length and short risers correspond to roughly to long (that of many risers in commercial use today), shorter, and short (under 1 second) residence times. Exact times are propriety 
information, however, it is the trends that are considered important here.

The most desirable product lumps are a little less than five extending up toward seven in this study. These include the usable dry gas, gasoline, and diesel fuel range. Figures 3 and 4 show in general that a decrease in residence time will decrease conversion and desirable product yields. Figure 4 , which has $\mathrm{C} / \mathrm{O}$ ratio of eleven, shows that at the higher $\mathrm{C} / \mathrm{O}$ ratio, conversion can be maintained at a good level, even at the shorter residence times. The lighter desirable product yields, around lump five, still drop, but the lowest at the higher $\mathrm{ClO}$ ratio (short residence time) is about the same as the highest at the lower $\mathrm{C} / \mathrm{O}$ ratio (long residence time). Mid-range product yields are either unaffected or increase slightly with shorter residence times (Figure 4). These results suggest that operating at higher $\mathrm{C} / \mathrm{O}$ ratios is one good way to optimize product yields for short residence time risers.

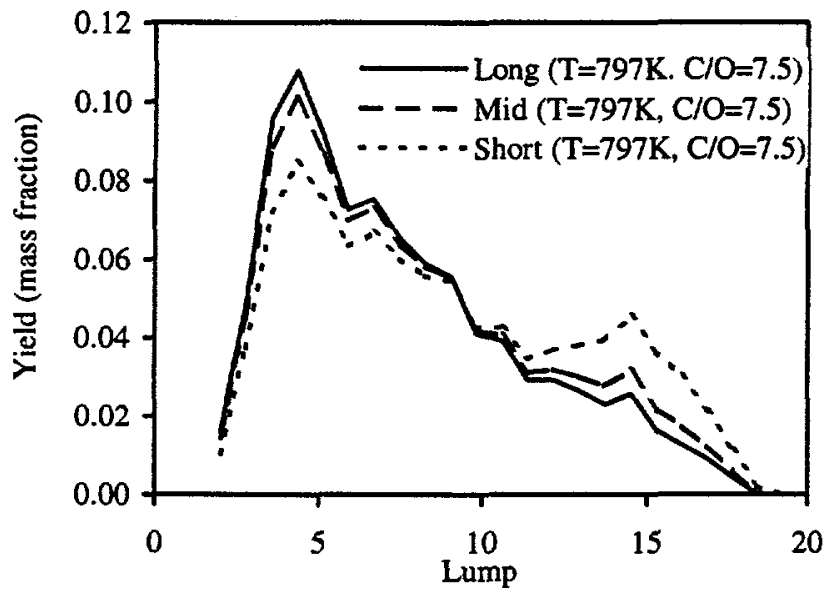

Figure 3 Effect of Residence Time On Yield Curve, Low C/O

A parametric study was done over a catalyst to oil ratio range from approximately 7 to 16 for both a short and long riser configuration. The short riser has a residence time less than $1 / 2$ that of the long riser. The primary purpose of the parametric study was to demonstrate that the optimum catalyst to oil ratio for gasoline product yield shifts to considerably higher catalyst to oil ratio when the residence time is significantly reduced. All operating conditions except riser length were kept the same for corresponding C/O ratios except for the riser length, which changed the residence time. Operating temperature and other parameters such as oil droplet size were not changed to bring the net conversion back up for the shorter riser.

Figure 5 shows gasoline product yield fraction plotted against $\mathrm{C} / \mathrm{O}$ ratio for both long and shor residence time risers. The figure clearly shows that there is an optimum gasoline yield over the range of $\mathrm{C} / \mathrm{O}$ ratios, and for the short residence time riser, the corresponding $\mathrm{C} / \mathrm{O}$ ratio to obtain optimum gasoline yield is significantly shifted to a higher value comparing to the long residence time riser.

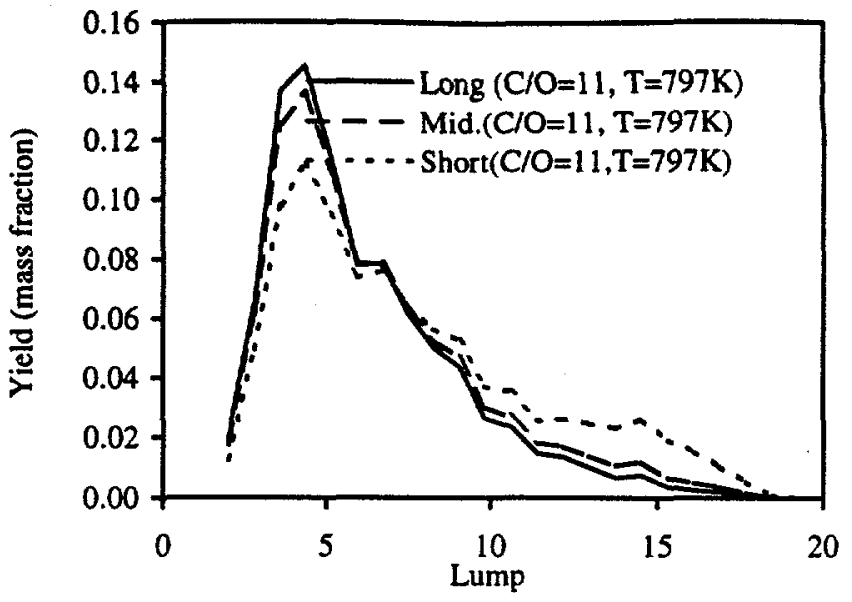

Figure 4 Effect of Residence Time On Yield Curve, High C/O

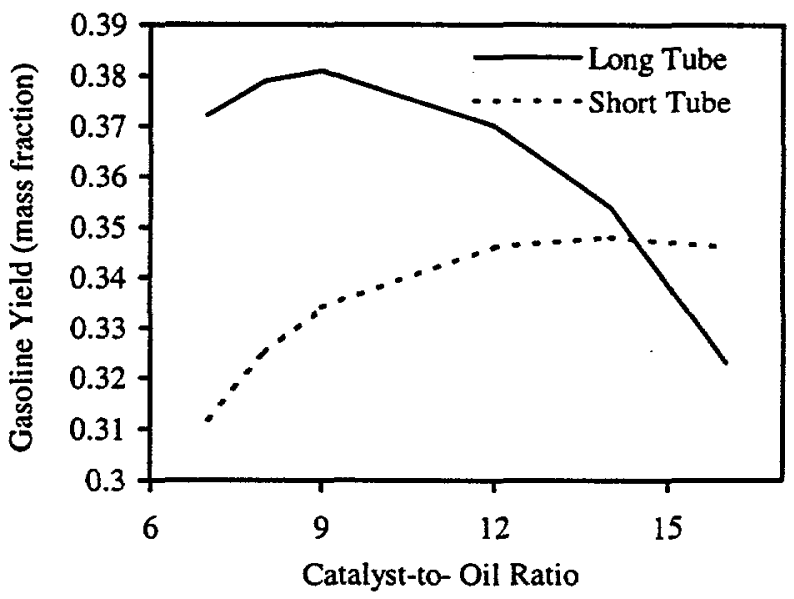

Figure 5 Effect of Residence Time On C/O Optimum for Gasoline

\section{C/O Ratio and Temperature Effects for a Short Residence Time Riser}

The effects of $\mathrm{C} / \mathrm{O}$ ratio and riser outlet temperature on the product yield curves for a short residence time riser (less than 1 second) are shown in Figures 6 and 7. In Figure 6, the significant role that $\mathrm{C} / \mathrm{O}$ ratio can play is very apparent. Conversion and desirable product yield are all brought up dramatically to good levels in the short residence time riser by increasing the $\mathrm{C} / \mathrm{O}$ ratio. Increasing temperature can also help bring yields up in a short residence time riser as shown in Figure 7. However, the heat balance in whole FCC system and limits on operating temperature in the regenerator can limit the increase possible in operating temperature to a greater degree than increases in $\mathrm{C} / \mathrm{O}$ ratio are limited by the requirement to maintain heat balance in the FCC system.

As seen in Figure 7, the yield gains in a short residence time riser due to increasing operating temperature within a reasonable range for 
the FCC system are definitely present, but much more moderate than the gains that appear possible by optimizing $\mathrm{C} / \mathrm{O}$ ratio.

Figure 8 shows the effect increasing temperature on the gasoline yield, which spans several lower midrange lumps. In this short residence time riser, a gasoline yield increase of about six percent is obtained with a riser exit temperature increase of about 45 degrees. In this fairly narrow range the temperature/yield relation for gasoline is approximately linear, but would not be expected to be linear over a significantly broader range. While this yield increase is much smaller than the yield increase obtained by changing $\mathrm{ClO}$ ratio, an increase of several percent in gasoline yield is still significant. Therefore, there does appear to be a benefit to operating short residence time FCC risers in the highest feasible temperature range.

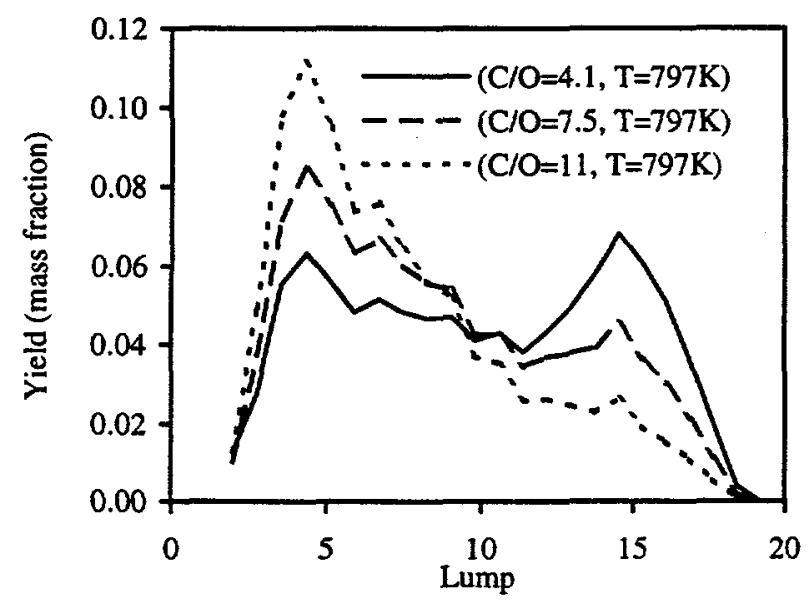

Figure 6 Effect of C/O Ratio On Yield Curve

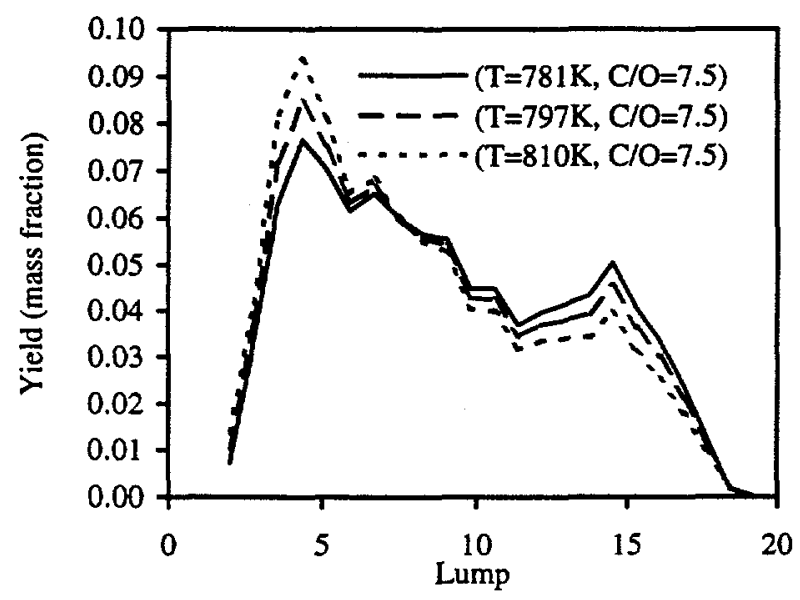

Figure 7 Effect of Temperature On Yield Curve

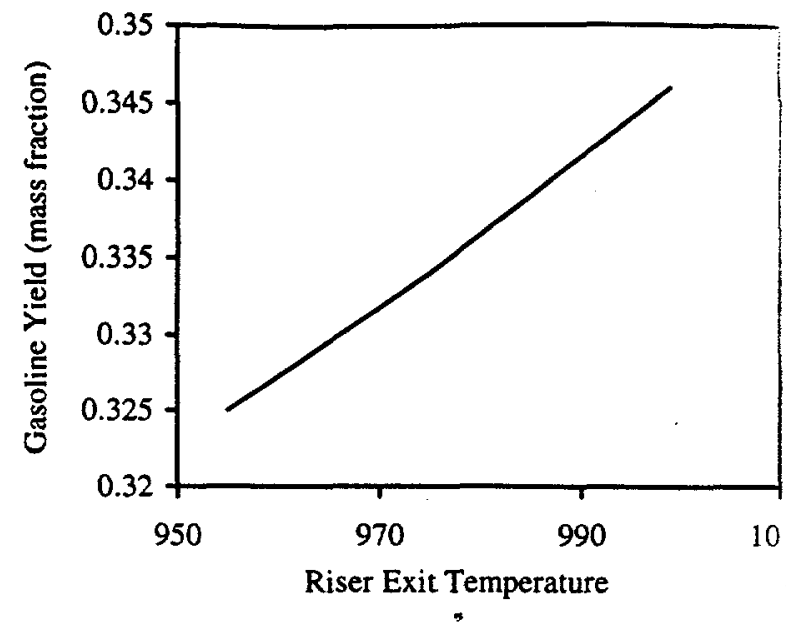

Figure 8 Effect of Temperature On Gasoline Yield Curve

\section{CONCLUSION}

A new modeling technique for computational analysis of three phase FCC riser flow and expanded detail lumped reaction kinetics has been developed and implemented in a CFD computer code, ICRKFLO. The expanded detail lumped reaction kinetics model is a generic lumped chemical kinetics model that can be adapted to a wide variety of particular FCC riser configurations with given feed stock and catalyst properties. The adaptation of the generic kinetics model is automated in an algorithm to determine kinetics constants for a potentially large number of reactions based on yield data collected over a relatively small set of operating conditions in ranges of interest. The kinetics model is validated against measurements at other points in the operating condition window. Parametric studies were done on the effects of catalyst to oil ratio, temperature, and FCC riser lengths (to vary residence time) on petroleum cracking yields. Results indicated that shortening the residence time may significantly reduce overall conversion and product yields for lighter desired products. Short residence time FCC risers appear to require a shift to significantly higher catalyst to oil ratios in order to maintain conversion and lighter desirable product yields.

\section{ACKNOWLEDGMENTS}

This work was supported by U.S. Department of Energy, Assistant Secretary for Energy Efficiency and Renewable Energy, under Contract W-31-109-ENG-38 and managed by Erh-Ping HuangFu of the Office of Industrial Technology.

\section{REFERENCES}

Chang, S.L., and C.S. Wang, "Thermal Radiation and Spray Group Combustion in Diesel Engines," ASME Winter Annual Meeting. Boston, Mass., HTD-81:25-34 (December 13-18, 1987).

Chang, S.L., and S.A. Lottes, "Characteristic of Multi-Phase Flow with Particle Evaporation in a Combustor with Counter-Flow Injection", Energy Convers. Mgmt, 36(11)1031-1045, (1995). 
Chang, S.L., and S.A. Lottes, "Integral Combustion Simulation of a Turbulent Reacting Flow in a Channel with Cross-Stream Injection," Numerical Heat Transfer Part A, 24(1):25-43 (1993).

Chang, S.L., S.A. Lottes, C.Q. Zhou, and M. Petrick, Evaluation of Multiphase Heat Transfer and Droplet Evaporation in Petroleum Cracking Flows, HTD-Vol. 335, Proceedings of the ASME Heat Transfer Division 4:17-27, International Mechanical Engineering Congress and Exposition, Atlanta, GA (November 17-22, 1996).

Chang, S.L., S.A. Lottes, and M. Petrick, "Development of a ThreePhase Reacting Flow Computer Model for Analysis of Petroleum Cracking," Proceedings of 1995 Mid-America Chinese Professional Annual Convention, Itasca, IL, pp.281-288 (June 23-25, 1995).

Dave, N.C., G.J. Duffy, and P. Udaja, "A Four-Lump Kinetic Model for the Cracking/Coking of Recycled Heavy Oil," Fuel, 72(9):1331-1334, (1993).

Lottes, S.A., and S.L. Chang, "Computer Simulation of Jet Penetration and Fluid Mixing in a Channel with Cross-Stream Jets," Proceedings of the 7th International Conference on Advanced Science and Technology, ANL, IL, pp.188-198, (1991).
Lottes. S.A., and S.L. Chang "Interactions of Turbulent Eddies and Combustion in an MHD Second Stage Combustor," Proceedings of the 26th Intersociety Energy Conversion Engineering Conference, Boston, MA, 3:69-74 (August 4-9, 1991).

Nigam, A., and M.T. Klein , "A Mechanism-Oriented Lumping Strategy for Heavy Hydrocarbon Pyrolysis: Imposition of Quantitative Structure-Reactivity Relationships for Pure Comonents," Ind. Eng. Chem. Res., 32:1297-1303,(1993).

Patankar, S.V., "Numerical Heat Transfer and Fluid Flow", Hemisphere, Washington, D.C. (1980).

Quann, R.J., and S.B. Jaffee, "Building Useful Models of Complex Reaction Systems in Petroleum Refining," Chemical Enginęering Science, 51(10):1615-1635, (1996).

Weekman, V.W. and D.M. Nace, "Kinetics of Catalytic Cracking Selectivity in Fixed, Moving, and Fluid Bed Reactors," AIChE Journal, 16(3):397-404, (1970).

Zhou, X.Q., and H.H. Chiu, "Spray Group Çombustion Processes in Air Breathing Propulsion Combustors," AIAA/SAE/ASME 19th Joint Propulsion Conference, Seattle, Washington, AIAA-83-1323, (1983). 